OPEN ACCESS

Edited by:

Artur Fedorowski,

Lund University, Sweden

Reviewed by:

Roland D. Thiis,

Leiden University Medical

Center, Netherlands

Blair Paul Grubb,

University of Toledo, United States

*Correspondence:

Robert S. Sheldon

sheldon@ucalgary.ca

Specialty section:

This article was submitted to

Cardiac Rhythmology,

a section of the journal

Frontiers in Cardiovascular Medicine

Received: 16 September 2019

Accepted: 14 November 2019

Published: 28 November 2019

Citation:

Sheldon RS and Sandhu RK (2019)

The Search for the Genes of Vasovagal Syncope.

Front. Cardiovasc. Med. 6:175. doi: 10.3389/fcrm.2019.00175

\section{The Search for the Genes of Vasovagal Syncope}

\author{
Robert S. Sheldon ${ }^{1,2 *}$ and Roopinder K. Sandhu ${ }^{1,2}$ \\ ${ }^{1}$ The Libin Cardiovascular Institute of Alberta, University of Calgary, Calgary, AB, Canada, ${ }^{2}$ The Mazankowski Heart Institute, \\ University of Alberta, Edmonton, $A B$, Canada
}

Only humans faint, and not all do so. Syncope tends to recur, and the predisposition to syncope can persist over many decades. Observations such as these have suggested that there may be a genetic predisposition to vasovagal syncope. It seems to have a high prevalence in some families; having a parent who faints increases the likelihood of an offspring fainting, and this is increased even further if both biological parents faint. Numerous studies have correlated a number of genotypes with positive tilt tests. However, the control subjects are usually those who faint, but have negative tilt tests, making the conclusions about association with the clinical phenotype less certain. Twin studies, highly focused genome-wide association studies, and gene duplicate studies all suggest there are sites in the genome that associate with vasovagal syncope, although the specific genes, pathways, and proteins are unknown. A recent large, candidate gene study of kindreds with high, multigenerational prevalence of the vasovagal syncope identified 3 genes that associate with vasovagal syncope. Our understanding of the genetic correlates of vasovagal syncope is in its infancy, with much to be understood.

\footnotetext{
Keywords: vasovagal syncope, genetics, kindreds, candidate gene, genome-wide association, syncope, vasovagal
}

\section{INTRODUCTION}

There are several reasons to suspect a genetic origin of vasovagal syncope. First, this appears to be a uniquely human response. First, there are no animals that faint (1), including closely related great apes. Second, not everyone faints. In countries such as Canada (2), the Netherlands (3), and Malaysia (4) there are similar proportions of lifetime syncope cumulative incidence, in the range of $25-35 \%$. Therefore, only a proportion of people appear to have vasovagal syncope. Third, the predisposition to syncope lasts decades for many people and the predisposition to syncope is an enduring phenotypic trait. Most fainters start fainting by age 30, and many clinical studies report syncope recurrences over subsequent decades (5). Similarly, the predisposition to faint on tilt table testing is generally reproducible (6). Similarly, non-inducibility is also stable. Furthermore, the degree of bradycardia induced by tilt testing is reproducible (6). Lastly, yet less persuasively, vasovagal syncope has no clearly associated autoimmune or infectious etiology.

Taken together, these 4 factors-the absence of syncope in other animals, only an affected minority of the population, persistent clinical, and physiologic phenotypes, and no apparent other cause-suggest a genetic origin for vasovagal syncope in humans.

More direct evidence for genetic associations with vasovagal syncope is accumulating. The essence of genetic analysis is to test the statistical strength of the association with the phenotype compared to a control population. These methods studying families with fainting members, testing the association of pre-specified candidate genes with the phenotype, and performing genome-wide 
association studies. These different methodologies can be applied in kindred studies, conceptually related syndromes, and population-wide studies. Most reports of vasovagal syncope have been candidate gene studies of the surrogate outcome of fainting on a tilt test. Uncovering genetic associations with vasovagal syncope may provide insights into the physiology of the reflex, and perhaps new targets for therapy. We'll review the evidence critically and suggest some approaches that could be explored, as well as potential limitations of these approaches.

\section{FAMILY PEDIGREE STUDIES}

Family pedigree studies examine how the phenotype occurs in multigenerational families, the likelihood that parents will appear to pass on the trait to their children, and occasionally the association of genotype and phenotype. The latter is helped because families share most other genes and this reduces background genetic variability, the noise in the signal. One important conceptual limitation is a statistical one: if vasovagal syncope has a lifetime cumulative incidence of $35 \%$, then if stochastic and not genetic there will be families with more than one fainting member, and the apparent inheritance pattern will be autosomal dominant. Simply reporting aggregated family histories cannot address this completely.

\section{Phenotypic Pedigrees}

Kleinknecht and Lenz (7) reported that $66 \%$ of people who fainted during exposure to blood or injury had at least one fainting parent compared to only $41 \%$ of control subjects $(p<$ 0.01 ). In a related study (8) Kleinknecht et al. reported that $94 \%$ of subjects with syncope in the absence of aversion to medical situations also had a family history of syncope. Marquez et al. (9) and Newton et al. $(10,11)$ have documented multigenerational pedigrees of families with numerous fainting members. The patterns were compatible with incomplete penetrance of an autosomal dominant pattern.

\section{Ensemble Family Histories}

With a lifetime cumulative incidence of $25-40 \%$ many families would be expected to have multiple fainting members by chance alone. Pooling family data is one approach to estimate the risk conferred by family histories on its members. Mathias et al. $(12,13)$ reported that $36-51 \%$ of fainting patients had a family members who fainted, compared to $28 \%$ of controls. Camfield and Camfield (14) reported an apparently autosomal dominance pattern the families who had children in school. Almost all fainting children had close family members who fainted, while only $33 \%$ of non-fainting probands had a family members who fainted. In contrast, Newton et al. (10) reported that fainting probands had only a $19 \%$ likelihood of fainting family members.

These studies have a number of limitations. Most had patients as index cases, raising the possibility of inclusion bias. Few had controls and or reproducible diagnostic criteria. None featured actuarial analysis, which is important in a syndrome in which the likelihood of fainting at least once increases with age. Finally, recall bias may be common, particularly in family histories of fainting.
We reported a community-based study of family histories of vasovagal syncope (2), featuring consenting second-year medical students and their first-degree relatives. The diagnosis of vasovagal syncope was confirmed with the Calgary Syncope Score, which has been used repeatedly and successfully in randomized clinical trials. By age 60 the likelihood of syncope was estimated to be $37 \%$, with $42 \%$ of females and $31 \%$ of males fainting. The likelihood of offspring fainting depended significantly on whether their parents fainted. For example, a man with two fainting parents is nearly 8 -fold more likely to faint than one neither of whose parents faint. Therefore, the likelihood of an individual fainting depends significantly on both sex and whether and how many parents faint. This does not prove that fainting is due to genes alone, and there almost certainly are substantial environmental factors.

\section{TWIN STUDIES}

Twins provide an interesting opportunity for efficient assessment of genetic sources of phenotypic traits. They are siblings, and therefore share not only much of their genetic information but also usually their environmental, social, educational, and financial background. Furthermore, they provide a unique experiment in nature of gene dosing: monozygotic genes share all their genetic information while non-identical twins share only half their genes.

Marquez et al. (9) and Arikan et al. (15) reported three sets of monozygotic twins with recurrent vasovagal syncope. One pair of female twins had fainting family members while the male twins did not. One set of monozygotic male twins both had documented asystole during syncope. Klein and Berkovic performed a much larger same-sex twins study (16) in which 51 sets of twins were recruited through the Australian Twins Registry, and in which at least one subject had fainted. The 19 identical (monozygous) twin pairs had significantly higher concordance in their histories of syncope, and 7 of these pairs had multiple affected family members. Taken together the twins data are compatible with a genetic association with vasovagal syncope, but far from establish its reality.

\section{CANDIDATE GENE ANALYSES}

A candidate gene analysis tests a specific hypothesis: does a particular allele associate significantly with a specific phenotypic trait? Typically a population of patients with the abnormal phenotype is compared to a control group. These have been very popular studies but are prone to several problems. They are univariable analyses, and usually do not include other and possibly important genotypic or phenotypic information. Candidate gene association studies by their nature study only the families at hand, making them are susceptible to local imbalances between the fainting and control groups, and external validity concerns when comparing the study population to different populations. Replication is critical (17). The generally small sample sizes mean that only relatively common alleles can be studied, with a minor allele frequency usually exceeding $10 \%$. 
Finally there is a persistent concern here as elsewhere about publication bias: well-done but negative studies struggle to find a home.

Most candidate gene studies of vasovagal syncope compared patients with positive tilt tests to those with negative tilt tests; in essence, a surrogate biomarker. We took a complementary approach by directly testing the association of 12 candidate gene alleles with clinical vasovagal syncope in 7 kindreds (18). The advantages of this approach are that we are studying clinical presentations and not surrogate markers, and kindred studies reduce the background variability in both genetic and environmental influences. We performed a candidate gene association study of 12 allelic variants with plausible connections to vasovagal syncope. The candidate alleles were targeted based on genetic and physiologic plausibility, and vasovagal syncope was ascertained with a validated questionnaire. One insertion/deletion promoter variant and 11 SNPs, including 2 promoter variants, were selected because they had a known physiologic effect, were plausibly relevant to vasovagal syncope physiology, and had a minor allelic frequency of at least $15 \%$. This frequency was chosen based on the results of an earlier family history study and a Mendelian model of autosomal dominance (2).

In this Candidate Gene section we'll review studies of vasovagal syncope and other disorders of hemodynamic control, using both surrogate studies and direct comparisons of patients and asymptomatic control subjects. Table 1 contains a compilation attempts to demonstrate associations between specific candidate genes and the susceptibility to the induction of vasovagal syncope on tilt tests.

\section{Alpha Adrenergic Receptors}

The alpha adrenergic 1 receptor ADRA1A 1039T $>C$ variant is involved in sympathetic transduction, and the Arg/Arg genotype of ADRA1A $1039 \mathrm{~T}>\mathrm{C}$ significantly associated with positive tilt tests when comparing vasovagal syncope patients to asymptomatic controls with negative tilt tests (29). However, it was unclear if the clinical variable was the vasovagal syncope phenotype or the positive tilt test. We found no evidence that this allele associates with vasovagal syncope subjects compared to unaffected family members (18). Our results suggest that the ADRA1A variant associates with positive tilt tests, but not with vasovagal syncope.

\section{Beta Adrenergic Receptors}

The beta adrenergic receptor ADRB1 $1165 \mathrm{G}>\mathrm{C}$ (30) and $145 \mathrm{~A}>\mathrm{G}(25)$ variants are involved in sympathetic transduction, might be involved in the vasovagal reflex. The genotypes of the beta adrenergic receptor gene ADRB1 $1165 G>C$ associated with positive tilt tests in syncope patients (30). However, the control population was syncope patients with negative tilt responses, not unaffected controls. Furthermore, neither we (18) nor others (25, 31) detected an association of the ADRB1 1165G $>C$ alleles with the clinical vasovagal phenotype when compared with unaffected control subjects.

Marquez et al. (30) studied the $\beta 1$-adrenoceptor polymorphism (Gly389Arg) in 50 syncope patients who had tilt tests. These
TABLE 1 | Associations between candidate gene alleles and susceptibility to induction of vasovagal syncope on tilt table tests.

\begin{tabular}{|c|c|c|}
\hline Gene & Protein & $\begin{array}{l}\text { Genotype-phenotype } \\
\text { association }\end{array}$ \\
\hline ACE & $\begin{array}{l}\text { Angiotensin converting } \\
\text { enzyme }\end{array}$ & Two negative $(19,20)$ \\
\hline AGT & Angiotensinogen & Negative (20) \\
\hline ATR1 & Angiotensin 2 receptor & Negative (20) \\
\hline EDN1 & Endothelin 1 & $\begin{array}{l}\text { Positive (21), negative } \\
\text { clinical }\end{array}$ \\
\hline EDNRA & Endothelin type A receptor & Negative (21) \\
\hline GNAS1 & G protein alpha & $\begin{array}{l}\text { One positive (22), one } \\
\text { negative (23) }\end{array}$ \\
\hline GNB3 & G protein Beta3 & $\begin{array}{l}\text { One positive (24), four } \\
\text { negative } \\
(22,23,25,26)\end{array}$ \\
\hline GNG2 & G protein $\gamma 2$ subunit & Negative (27) \\
\hline RGS2 & G protein signaling regulator & $\begin{array}{l}\text { Three negative } \\
(22,23,28)\end{array}$ \\
\hline ADRA1A & Alpha1 adrenergic receptor & $\begin{array}{l}\text { One negative (25), one } \\
\text { positive (29) }\end{array}$ \\
\hline ADRB1 & Beta1 adrenergic receptor & $\begin{array}{l}\text { Two positive }(29,30) \text {, } \\
\text { two negative }(25,31)\end{array}$ \\
\hline ADRB2 & Beta2 adrenergic receptor & Negative (25) \\
\hline ADORA2A & Adenosine receptor $\mathrm{A} 2 \mathrm{~A}$ & Positive (32) \\
\hline SERT & Serotonin transporter & Two negative $(20,25)$ \\
\hline $\mathrm{DBH}$ & Dopamine beta hydroxylase & Negative (25) \\
\hline CHRM2 & Muscarinic M2 receptor & Negative (27) \\
\hline KCNJ3 & $\begin{array}{l}\text { Potassium inwardly } \\
\text { rectifying channel, subfamily } \\
\text { J, member } 3\end{array}$ & Negative (27) \\
\hline KCNJ5 & $\begin{array}{l}\text { Potassium inwardly } \\
\text { rectifying channel, subfamily } \\
\text { J, member } 5\end{array}$ & Negative (27) \\
\hline
\end{tabular}

polymorphisms were studied because of the role of beta adrenergic stimulation in inducing vasovagal syncope during tilt testing (33), and because the 389Arg allele may increase sensitivity to $\beta$-adrenergic stimulation (34). The results were in complete contrast to the apparent hypothesis, and in fact the allele was equally prevalent in syncope patients and in larger normal populations. In the candidate gene kindred analysis (18) there was no evidence for the association of either allele with vasovagal syncope. Therefore, the Arg389Gly allele of the $\beta 1$ adrenoceptor may make a positive tilt test more likely but does not seem to predispose to clinical vasovagal syncope.

\section{G Protein Signaling}

The beta-adrenergic G alpha subunit GNAS1 351C>T variant (35) is involved in sympathetic transduction, and is linked to orthostatic intolerance. We found no evidence that this allele associates with vasovagal syncope subjects compared to unaffected family members. Our results suggest that the ADRA1A variant is not associated with vasovagal syncope. Similarly, the TT genotype of GNAS1 T393C associates with less hypotension in patients with orthostatic hypotension (35), but 
not with tilt test outcome in patients with presumed vasovagal syncope (23). Finally, Lelonek et al. reported that 825TT genotype of GNB3, the G protein beta 3 subunit predicts negative tilt test result in syncope patients (23). We did not test this genotype. They also reported the association of the 825T allele with atypical histories of vasovagal syncope.

\section{Adenosine Receptors}

The adenosine 2A receptor ADORA2A 1083T>C (formerly 1364 $T>C$ ) variant (32) is involved in adenosine transduction, and is linked to orthostatic hypotension and bradycardia. The $\mathrm{C} / \mathrm{C}$ genotype of the adenosine receptor ADORA2A 1083T $>C$ associates with positive tilt tests (32). We found no evidence that this allele associates with vasovagal syncope subjects compared to unaffected family members (18). Our results indicate that the ADORA2A variant associates with positive tilt tests, but not with vasovagal syncope.

\section{Vasoactive Receptors}

Newton et al. (19) reported that a polymorphism in the angiotensin-converting enzyme was approximately equally prevalent in syncope patients with a positive tilt test and in the normative population, making it an unlikely candidate for a gene that causes vasovagal syncope. Arterial vasoconstriction is impaired in young vasovagal syncope patients, and that this is prevented by NOS inhibition (36). eNOS3 $(-786) \mathrm{T}>\mathrm{C}$ and $894 \mathrm{~T}>\mathrm{G}$ variants associate with Postural Tachycardia Syndrome (37). However, we found no evidence that this allele associates with vasovagal syncope subjects compared to unaffected family members (18).

\section{Serotonin Signaling}

We identified 3 gene variants in serotonin and dopamine signaling that appear to be associated with the phenotype of vasovagal syncope. The serotonin $5 \mathrm{HT} 1 \mathrm{~A}$ receptor is linked to vasodilation, might be involved in the vasovagal reflex (38-40), and the $(-1019) \mathrm{G}>\mathrm{C}$ promoter variants regulate receptor levels. The serotonin reuptake transporter long/short promoter variant modulates serotonin signaling, and is linked to positive tilt test phenotype (41). Catecholamine O-methyltransferase degrades dopamine, and thereby reduces serotonin release into the synapse $(42,43)$. The serotonin 5HT1A receptor (-1019) G allele strongly associates with syncope in males but has the opposite effect females $(p=0.005)$. The serotonin transporter promoter long alleles associate with a decreased likelihood of fainting in males but increased in females. Males with homozygous long and short promoter alleles had 25 and $47 \%$ likelihoods of fainting, respectively, while in females had the likelihoods were 75 and $50 \%$. The catechol O-methyltransferase c.472 A alleles were significantly linked with a decreased likelihood of fainting in males but the opposite in females $(p=0.017)$. This effect of serotonin signaling alleles on vasovagal syncope supports the serotonin hypothesis of the physiology of vasovagal syncope.

\section{Candidate Genes and Serotonin Model}

These findings support a model in which serotonin binding to post-synaptic $5 \mathrm{HT} 1 \mathrm{~A}$ receptors causes vasovagal syncope by inducing hypotension and bradycardia $(40,41)$. The possible interactions of serotonin signaling and vasovagal syncope have been noted for decades. One of the clearest series studies demonstrated that acute intravenous administration of clomipramine, a highly specific serotonin transporter inhibitor, provoked vasovagal syncope on tilt tests $(41,44,45)$. Therefore, acutely increased intrasynaptic serotonin is associated with the vasovagal response. Randomized clinical trials of serotonin transport inhibitors have provided mixed results (46-48), but two good studies have been positive. Our work does provide one conceptual framework for this field, but much uncertainty remains.

\section{GENOME-WIDE ASSOCIATION STUDIES}

Genome-wide association studies, or GWAS, rely on the presence of millions of single nucleotide polymorphisms, or SNPs, scattered in the genome, all of whose positions on chromosomes are known. Studies search for highly significant statistical significance between specific SNPs and the phenotypes of interest. Generally because so many SNPs are studied simultaneously the threshold for statistical significance is extraordinarily high, often $10^{-8}$ or higher. As well, GWAS studies usually require replication, and usually thousands or tens of thousands of subjects are required in both the trait and control populations. It is not uncommon to have very many SNPs have phenotype associations with statistical significances of $10^{-6}$. Although initially this was thought to be simply generated by the very large number of SNPs being studied this might not be so. The understanding that phenotypes arise from networks of gene and protein interactions has led to the concept of omnigenics (49), which proposes that very high numbers of genes underlie traits. In this paradigm GWAS studies target only the most influential of many genes.

\section{Copy Number Variants}

Copy number variants are contiguous sequences of several 100 kilobases that occur in more than 2 copies per genome. Demir et al. (50) studied the distribution of copy number variants throughout the genome of 16 subjects with vasovagal syncope and 3 controls, all within 4 families. In this small study there were 26 copy number variants whose distributions varied between syncope subjects, controls, and a publicly referenced database. The interpretation was made difficult because the variants occurred on all chromosomes, the distributions differed among all subjects, some increased in number while others decreased, and some had longer contiguous stretches while others decreased in length.

\section{Biobank GWAS}

Hadji-Turdeghal et al. (51) attempted to use GWAS to identify a genetic locus for syncope. They studied very large biobanks and databases in the United Kingdom and Denmark. The Danish population had a majority of patients with at least one of six major mental illnesses such as autism and schizophrenia. Only one locus, at chromosomal location 2q32.1, was highly significantly associated with identified syncope. The nearest 
known structural gene was ZNF804A, which codes for a zinc finger regulatory protein. However, only $2.2 \%$ of the UK population and $6.5 \%$ of the Danish population were identified as having syncope, suggesting that syncope was under-reported in the control populations. The biological relevance of this is tantalizing but its clinical reality and significance are yet to be determined.

\section{Single Family GWAS}

Klein et al. (52) studied 44 Australian families with a familial history of syncope and identified 6 families with apparent autosomal dominant inheritance. Microsatellite markers identified in the largest family an apparent locus in chromosome locus $15 \mathrm{q} 26$, but sequencing of nearby candidate genes did not reveal mutations. Four affected members in this family did not carry the 15q26 haplotype, and the two next largest affected families did not carry this haplotype either. The relevance of this isolated finding remains to be determined.

\section{FUTURE PERSPECTIVES}

The evidence to date is compatible with one or more genetic sources of the vasovagal reflex. However, the studies to date are plagued by incomplete case finding, inadequate and irreproducible case definitions, limited definition of what is normal, low sample sizes, the use of surrogate outcomes that have not been substantiated in clinical studies, and the predominance of univariable candidate gene analyses. It may also be that the omnigenic or heavily polygenic paradigms are the case, and

\section{REFERENCES}

1. van Dijk JG. Fainting in animals. Clin Auton Res. (2003) 13:24755. doi: 10.1007/s10286-003-0099-1

2. Serletis A, Rose S, Sheldon AG, Sheldon RS. Vasovagal syncope in medical students and their first-degree relatives. Eur Heart J. (2006) 27:196570. doi: 10.1093/eurheartj/ehl147

3. Colman N, Nahm K, Ganzeboom KS, Shen WK, Reitsma J, Linzer M, et al. Epidemiology of reflex syncope. Clin Auton Res. (2004) 14 (Suppl. 1):917. doi: 10.1007/s10286-004-1003-3

4. Tan MP, Ho YY, Chin AV, Saedon N, Abidin IZ, Chee KH, et al. Ethnic differences in lifetime cumulative incidence of syncope: the Malaysian elders longitudinal research (MELoR) study. Clin Auton Res. (2019) doi: 10.1007/s10286-019-00610-2. [Epub ahead of print].

5. Sheldon RS, Grubb BP, Olshansky B, Shen WK, Calkins H, Brignole M, et al. 2015 Heart Rhythm Society Expert Consensus Statement on the diagnosis and treatment of postural tachycardia syndrome, inappropriate sinus tachycardia, and vasovagal syncope. Heart Rhythm. (2015) 12:e4163. doi: 10.1016/j.hrthm.2015.03.029

6. Sheldon R, Splawinski J, Killam S. Reproducibility of isoproterenol tilttable tests in patients with syncope. Am J Cardiol. (1992) 69:13005. doi: 10.1016/0002-9149(92)91225-S

7. Kleinknecht RA, Lenz J. Blood/injury fear, fainting and avoidance of medically-related situations: a family correspondence study. Behav Res Ther. (1989) 27:537-47. doi: 10.1016/0005-7967(89)90088-0

8. Kleinknecht RA, Lenz J, Ford G, DeBerard S. Types and correlates of blood/injury-related vasovagal syncope. Behav Res Ther. (1990) 28:28995. doi: 10.1016/0005-7967(90)90080-3

9. Marquez MF, Urias KI, Hermosillo AG, Jardon JL, Iturralde P, Colin L, et al. Familial vasovagal syncope. Europace. (2005) 7:472-4. doi: 10.1016/j.eupc.2005.05.004 numerous genes each with small effects combine to predispose people to the vasovagal reflex. However, if there is a small number of genetic loci involved then the following criteria should be met to decide that a genetic locus is importantly involved.

1. The diagnosis should be established firmly in subjects with syncope by an evidence-based history or tilt test or documented vital signs during a syncopal spell;

2. The core abnormal allele should be present in all subjects with vasovagal syncope;

3. The core abnormal allele should be absent in most subjects without vasovagal syncope;

4. The difference between subjects with vasovagal syncope and controls should be based on clinical history and not a surrogate outcome such as a tilt table test;

5. Control subjects should be at least 50 years old, given that most (but not all) subjects with vasovagal syncope have a first syncopal spell before age 50 ;

6. The genetic locus should be associated with syncope in both sexes and in multiple ethnic populations;

7. There may be modifying loci that differ between males and females;

8. The findings must be reproducible in adequately powered studies.

\section{AUTHOR CONTRIBUTIONS}

All authors listed have made a substantial, direct and intellectual contribution to the work, and approved it for publication.

10. Newton JL, Kenny R, Lawson J, Frearson R, Donaldson P, Newcastle C. Prevalence of family history in vasovagal syncope and haemodynamic response to head up tilt in first degree relatives: preliminary data for the Newcastle cohort. Clin Auton Res. (2003) 13:22-6. doi: 10.1007/s10286-003-0077-7

11. Newton JL, Kerr S, Pairman J, McLaren A, Norton M, Kenny RA, et al. Familial neurocardiogenic (vasovagal) syncope. Am J Med Genet A. (2005) 133A:176-9. doi: 10.1002/ajmg.a.30572

12. Mathias CJ, Deguchi K, Schatz I. Observations on recurrent syncope and presyncope in 641 patients. Lancet. (2001) 357:34853. doi: 10.1016/S0140-6736(00)03642-4

13. Mathias CJ, Deguchi K, Bleasdale-Barr K, Kimber JR. Frequency of family history in vasovagal syncope.[letter]. Lancet. (1998) 352:33-4. doi: 10.1016/S0140-6736(05)79513-1

14. Camfield PR, Camfield CS. Syncope in childhood: a case control clinical study of the familial tendency to faint. Can J Neurol Sci. (1990) 17:3068. doi: $10.1017 /$ S0317167100030626

15. Arikan E, Yeşil M, Apali Z, Postaci N, Bayata S. Vasovagal syncope in monozygotic twins. Anadolu Kardiyol Derg. (2009) 9:61-2.

16. Klein KM, Berkovic SF. Genetics of vasovagal syncope. Auton Neurosci. (2014) 184:60-5. doi: 10.1016/j.autneu.2014.03.008

17. Association of genetic loci: replication or not, that is the question. [editorial]. Neurology. (2004) 63:955. doi: 10.1212/WNL.63.6.955

18. Sheldon R, Rose MS, Ritchie D, Martens K, Maxey C, Jagers J, et al. Genetic association study in multigenerational kindreds with vasovagal syncope. Circ Arrhythm Electrophysiol. (2019) 12:e006884. doi: 10.1161/CIRCEP.118.006884

19. Newton JL, Donaldson P, Parry S, Kenny RA, Smith J, Gibson AM, et al. Angiotensin converting enzyme insertion/deletion polymorphisms in vasovagal syncope. Europace. (2005) 7:396-9. doi: 10.1016/j.eupc.2005. 03.001 
20. Mudrakova K, Mitro P, Salagovic J, Habalova V, Kirsch P, Tkac I. Gene polymorphisms of renin angiotensin system and serotonin transporter gene in patients with vasovagal syncope. Bratisl Lek Listy. (2009) 110:73-6.

21. Sorrentino S, Forleo C, Iacoviello M, Guida P, D'Andria V, Favale S. Endothelin system polymorphisms in tilt test-induced vasovagal syncope. Clin Auton Res. (2009) 19:123-9. doi: 10.1007/s10286-009-0008-3

22. Lelonek M, Pietrucha T, Matyjaszczyk M, Goch JH. Genetic insight into syncopal tilted population with severe clinical presentation. Auton Neurosci. (2009) 147:97-100. doi: 10.1016/j.autneu.2009.01.011

23. Lelonek M, Pietrucha T, Matyjaszczyk M, Goch JH. A novel approach to syncopal patients: association analysis of polymorphisms in G-protein genes and tilt outcome. Europace. (2009) 11:89-93. doi: 10.1093/europace/eun277

24. Lelonek M, Pietrucha T, Stanczyk A, Goch JH. Vasovagal syncope patients and the C825T GNB3 polymorphism. Anadolu Kardiyol Derg. (2007) 7 (Suppl. 1):206-8.

25. Sorrentino S, Forleo C, Iacoviello M, Guida P, D'Andria V, Favale S. Lack of association between genetic polymorphisms affecting sympathetic activity and tilt-induced vasovagal syncope. Auton Neurosci. (2010) 155:98103. doi: 10.1016/j.autneu.2010.01.002

26. Lelonek M, Pietrucha T, Matyjaszczyk M, Goch JH. C825T G-protein beta3 subunit gene polymorphism, tilt test results and point score in syncopal patients. Clin Auton Res. (2008) 18:158-61. doi: 10.1007/s10286-008-0474-z

27. Holmegard HN, Benn M, Mehlsen J, Haunsø S. Genetic variation in the parasympathetic signaling pathway in patients with reflex syncope. Genet $\mathrm{Mol}$ Res. (2013) 12:2601-10. doi: 10.4238/2013.January.30.6

28. Lelonek M, Pietrucha T, Matyjaszczyk M, Goch JH. Polymorphism C1114G of gene encoding the cardiac regulator of G-protein signaling 2 may be associated with number of episodes of neurally mediated syncope. Arch Med Res. (2009) 40:191-5. doi: 10.1016/j.arcmed.2009.02.005

29. Hernandez-Pacheco G, Gonzalez-Hermosillo A, Murata C, Yescas P, Espinola-Zavaleta N, Martinez M, et al. Arg347Cys polymorphism of alphala-adrenergic receptor in vasovagal syncope. Casecontrol study in a Mexican population. Auton Neurosci. (2014) 183:66-71. doi: 10.1016/j.autneu.2014.01.005

30. Márquez MF, Hernández-Pacheco G, Hermosillo AG, Gómez JR, Cárdenas M, Vargas-Alarcón G. The Arg389Gly beta1-adrenergic receptor gene polymorphism and susceptibility to faint during head-up tilt test. Europace. (2007) 9:585-8. doi: 10.1093/europace/eum059

31. Zelazowska M, Lelonek M, Fendler W, Pietrucha T. Arg389Gly $\beta 1$-adrenergic receptor polymorphism and susceptibility to syncope during tilt test. Arch Med Sci. (2014) 10:240-5. doi: 10.5114/aoms.2014.42576

32. Saadjian AY, Gerolami V, Giorgi R, Mercier L, Berge-Lefranc JL, Paganelli F, et al. Head-up tilt induced syncope and adenosine A2A receptor gene polymorphism. Eur Heart J. (2009) 30:1510-5. doi: 10.1093/eurheartj/ehp126

33. Sheldon R, Killam S. Methodology of isoproterenol-tilt table testing in patients with syncope. J Am Coll Cardiol. (1992) 19:773-9. doi: 10.1016/0735-1097(92)90517-Q

34. Bruck H, Leineweber K, Temme T, Weber M, Heusch G, Philipp T, et al. The Arg389Gly beta1-adrenoceptor polymorphism and catecholamine effects on plasma-renin activity. J Am Coll Cardiol. (2005) 46:21115. doi: 10.1016/j.jacc.2005.08.041

35. Tabara Y, Kohara K, Miki T. Polymorphisms of genes encoding components of the sympathetic nervous system but not the renin-angiotensin system as risk factors for orthostatic hypotension. J Hypertens. (2002) 20:6516. doi: 10.1097/00004872-200204000-00022

36. Stewart JM, Medow MS, Sutton R, Visintainer P, Jardine DL, Wieling W. Mechanisms of vasovagal syncope in the young: reduced systemic vascular resistance versus reduced cardiac output. J Am Heart Assoc. (2017) 6:e004417. doi: 10.1161/JAHA.116.004417

37. Garland EM, Winker R, Williams SM, Jiang L, Stanton K, Byrne DW, et al. Endothelial NO synthase polymorphisms and postural tachycardia syndrome. Hypertension. (2005) 46:1103-10. doi: 10.1161/01.HYP.0000185462.08685.da

38. Albert PR, Le Francois B, Millar AM. Transcriptional dysregulation of 5-HT1A autoreceptors in mental illness. Mol Brain. (2011) 4:21. doi: 10.1186/1756-6606-4-21
39. Horiuchi J, Atik A, Iigaya K, McDowall LM, Killinger S, Dampney RA. Activation of 5-hydroxytryptamine-1A receptors suppresses cardiovascular responses evoked from the paraventricular nucleus. Am J Physiol Regul Integr Comp Physiol. (2011) 301:R1088-97. doi: 10.1152/ajpregu.00144.2011

40. Watts SW, Morrison SF, Davis RP, Barman SM. Serotonin and blood pressure regulation. Pharmacol Rev. (2012) 64:359-88. doi: 10.1124/pr.111. 004697

41. Theodorakis GN, Markianos M, Zarvalis E, Livanis EG, Flevari P, Kremastinos DT. Provocation of neurocardiogenic syncope by clomipramine administration during the head-up tilt test in vasovagal syndrome. J Am Coll Cardiol. (2000) 36:174-8. doi: 10.1016/S0735-1097(00)00719-1

42. Miguelez C, Benazzouz A, Ugedo L, De Deurwaerdère P. Impairment of serotonergic transmission by the antiparkinsonian drug L-DOPA: mechanisms and clinical implications. Front Cell Neurosci. (2017) 11:274. doi: 10.3389/fncel.2017.00274

43. Xie T, Ho SL, Ramsden D. Characterization and implications of estrogenic down-regulation of human catechol-O-methyltransferase gene transcription. Mol Pharmacol. (1999) 56:31-8. doi: 10.1124/mol.56.1.31

44. Theodorakis GN, Livanis EG, Leftheriotis D, Flevari P, Markianos M, Kremastinos DT. Head-up tilt test with clomipramine challenge in vasovagal syndrome-a new tilt testing protocol. Eur Heart J. (2003) 24:65863. doi: 10.1016/S0195-668X(02)00821-7

45. Theodorakis GN, Markianos M, Livanis EG, Zarvalis E, Flevari P, Kremastinos DT. Central serotonergic responsiveness in neurocardiogenic syncope: a clomipramine test challenge. Circulation. (1998) 98:272430. doi: 10.1161/01.CIR.98.24.2724

46. Di Girolamo E, Di Iorio C, Sabatini P, Leonzio L, Barbone C, Barsotti A. Effects of paroxetine hydrochloride, a selective serotonin reuptake inhibitor, on refractory vasovagal syncope: a randomized, double-blind, placebo-controlled study. J Am Coll Cardiol. (1999) 33:1227-30. doi: 10.1016/S0735-1097(98)00694-9

47. Takata TS, Wasmund SL, Smith ML, Li JM, Joglar JA, Banks K, et al. Serotonin reuptake inhibitor (Paxil) does not prevent the vasovagal reaction associated with carotid sinus massage and/or lower body negative pressure in healthy volunteers. Circulation. (2002) 106:1500-4. doi: 10.1161/01.CIR.0000029748.94931.96

48. Theodorakis GN, Leftheriotis D, Livanis EG, Flevari P, Karabela G, Aggelopoulou N, et al. Fluoxetine vs. propranolol in the treatment of vasovagal syncope: a prospective, randomized, placebo-controlled study. Europace. (2006) 8:193-8. doi: 10.1093/europace/euj041

49. Boyle EA, Li YI, Pritchard JK. An expanded view of complex traits: from polygenic to omnigenic. Cell. (2017) 169:117786. doi: 10.1016/j.cell.2017.05.038

50. Demir E, Hasdemir C, Ak H, Atay S, Aydin HH. Genome-Wide Association Study of copy number variations in patients with familial neurocardiogenic syncope. Biochem Genet. (2016) 54:487-94. doi: 10.1007/s10528-016-9735-Z

51. Hadji-Turdeghal K, Andreasen L, Hagen CM, Ahlberg G, Ghouse J, Bækvad-Hansen $\mathrm{M}$, et al. Genome-wide association study identifies locus at chromosome 2q32.1 associated with syncope and collapse. Cardiovasc Res. (2019) cvz106. doi: 10.1093/cvr/cvz106. [Epub ahead of print].

52. Klein KM, Bromhead CJ, Smith KR, O'Callaghan CJ, Corcoran SJ, Heron SE, et al. Autosomal dominant vasovagal syncope: clinical features and linkage to chromosome 15q26. Neurology. (2013) 80:1485-93. doi: 10.1212/WNL.0b013e31828cfad0

Conflict of Interest: The authors declare that the research was conducted in the absence of any commercial or financial relationships that could be construed as a potential conflict of interest.

Copyright (C) 2019 Sheldon and Sandhu. This is an open-access article distributed under the terms of the Creative Commons Attribution License (CC BY). The use, distribution or reproduction in other forums is permitted, provided the original author(s) and the copyright owner(s) are credited and that the original publication in this journal is cited, in accordance with accepted academic practice. No use, distribution or reproduction is permitted which does not comply with these terms. 